\title{
Is COVID-19 the current world-wide pandemic having effects on the profile of psychoactive substance poisonings?
}

\author{
Bruno Pereira dos Santos ${ }^{1,3} \cdot$ Giovanna Cristiano de Gouveia ${ }^{1,2,3} \cdot$ Sarah Eller $^{1}$ - Ana Miguel Fonseca Pego ${ }^{4}$. \\ Viviane Cristina Sebben ${ }^{2} \cdot$ Tiago Franco de Oliveira $^{1}[$
}

Received: 16 September 2020 / Accepted: 2 October 2020 / Published online: 8 November 2020

(c) Japanese Association of Forensic Toxicology 2020

\section{Dear Editor,}

Recent times have shown an increasing number of intoxication cases, resulting in damaging public health issues all around the globe, and Brazil is not an exception [1]. Most of the cases observed denoted the use of psychoactive substances, such as recreational drugs and medication for psychiatric use [2]. Currently, with the COVID-19 pandemic, both strict lockdown and general social distance rules have been recommended. The application of such public health control measures resulted in personal behavior alterations, considering that, during quarantine, individuals find themselves deprived of any social interactions, which can ultimately modulate the profile of poisonings [3].

The present study seeks to verify possible temporal changes in the poisoning profiles of Rio Grande do Sul state, southern Brazil, due to the COVID-19 outbreak. For this purpose, data was gathered from cases of intoxication by the five main classes of psychoactive substances: anticonvulsants, antidepressants, antipsychotics, benzodiazepines, and recreational drugs, arriving at the Toxicological Information Center of Rio Grande do Sul, from March to July 2019

Bruno Pereira dos Santos and Giovanna Cristiano de Gouveia contributed equally to this article.

Tiago Franco de Oliveira

oliveira@ufcspa.edu.br

1 Pharmacosciences Department, Federal University of Health Sciences of Porto Alegre, Porto Alegre, RS 90050-170, Brazil

2 Toxicological Information Center of Rio Grande Sul, Porto Alegre, RS 90610-000, Brazil

3 Voluntary Research Service, National Secretariat for Drug Policies, Ministry of Justice and Public Security, Federal Government of Brazil, Brasilia, DF 70064-900, Brazil

4 Dutch Screening Group, Maastricht 6229 GS, The Netherlands and from March to July 2020 (Table 1). The data analyzed are comprised of a wide range of incidents, verified by the many variables obtained, such as age, gender, circumstance of exposure, and location of exposure. Out of the 8588 cases attended by our team during the quarantine, a reduction of $-6 \%$ in comparison with the same period in the last year was observed; 3179 cases were included in the five classes of substances evaluated. As for the four classes of psychiatric drugs tested, their combined number decreased by $-8.4 \%$, while illicit drugs and alcohol intoxications alone rose by $+41.4 \%$. The reported numbers clearly indicated a change in poisoning profile as compared to 2019.

Within recreational drugs (alcohol, amphetamine, cocaine, ecstasy/MDMA, inhalants, LSD, and marijuana), the highest incidence of cases were alcohol, from 94 to 137 cases $(+45.7 \%)$ and cocaine, from 62 to 91 cases $(+46.8 \%)$. A substantial increase was also found for other substances such as marijuana which rose from 17 to 27 cases (+58.8\%) and ecstasy/MDMA, from 5 to 9 cases $(+80.0 \%)$. Situations generated by the pandemic, such as stress, isolation, and financial insecurity can result in increased alcohol and drug consumption and misuse $[4,5]$, thus explaining an expected rise in intoxication cases.

Unlike recreational drugs, a medication used for psychiatric treatment showed a decrease. The class of antidepressants presented an expressive reduction, of $-17.6 \%$, followed by anticonvulsants $(-10.1 \%)$, benzodiazepines $(-2.1 \%)$, and antipsychotics $(+1.0 \%)$, given that the last two maintained a certain stability in comparison with the remaining substances. Within the class of antidepressants, the compounds with the highest incidence were fluoxetine, which decreased from 302 to 266 cases ( $-11.9 \%$ ); amitriptyline also showed a reduction from 255 to 204 cases $(-20.0 \%)$, and finally sertraline from 157 to 135 cases $(-14.0 \%)$ reported. As for anticonvulsants, these have shown a much lower absolute reduction, with carbamazepine, from 158 to 143 cases ( $-9.5 \%)$, valproic acid, from 143 to 137 cases $(-4.2 \%)$, 


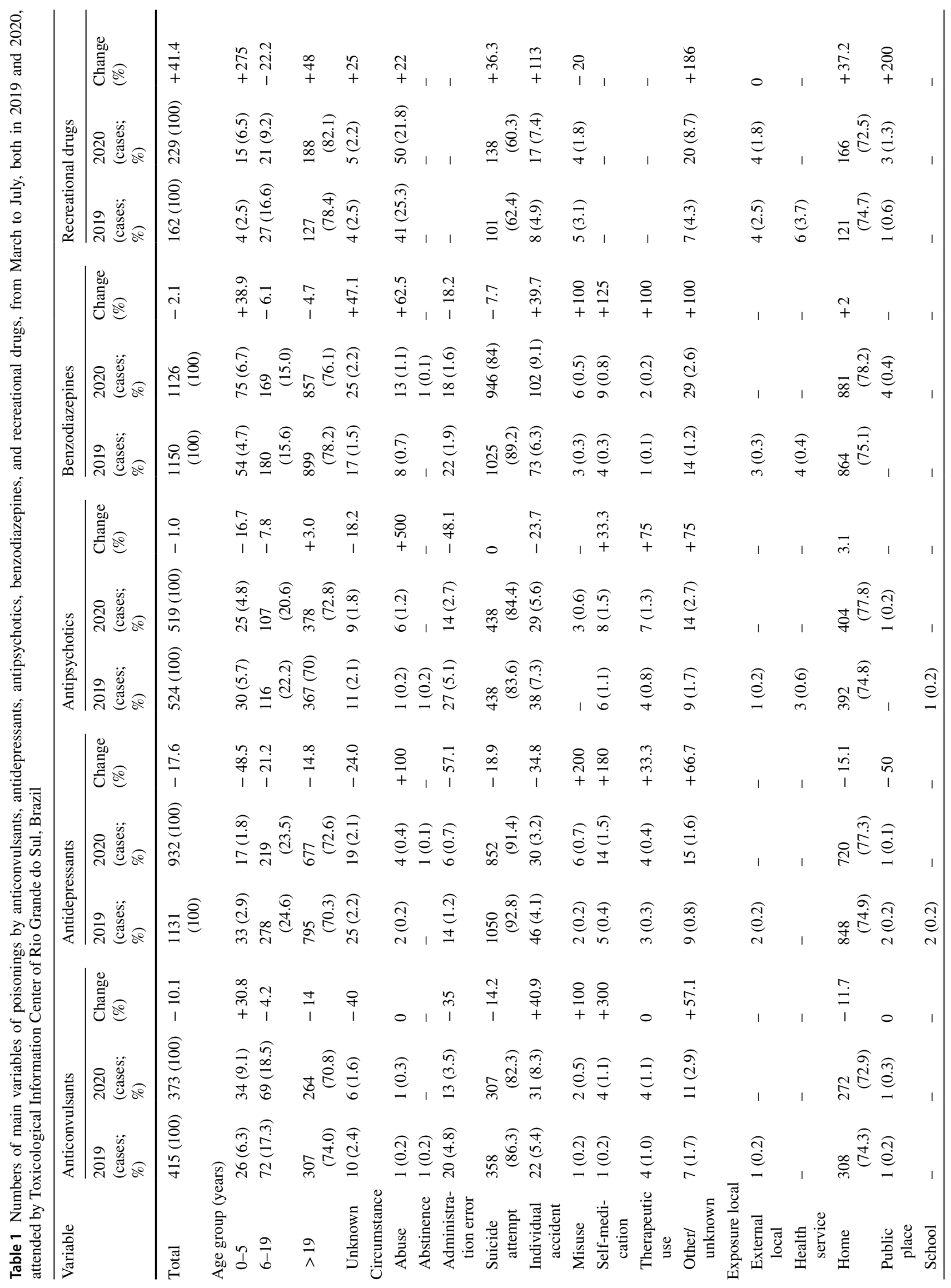




\begin{tabular}{|c|c|c|c|}
\hline & $\begin{array}{l}\text { 品 } \\
\text { 胥 } \\
\text { త }\end{array}$ & $\begin{array}{l}\hat{\delta} \\
\infty \\
+\end{array}$ & $\begin{array}{c}m \\
\infty \\
+ \\
+\end{array}$ \\
\hline 点 & 空 & 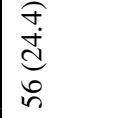 & 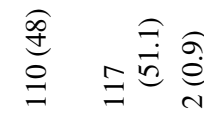 \\
\hline : & 苍 & \begin{tabular}{|l}
$n$ \\
$n$ \\
$\infty$ \\
0 \\
0 \\
0 \\
$n$
\end{tabular} & 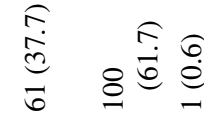 \\
\hline & 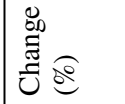 & $\begin{array}{l}0 \\
\ddot{2} \\
1\end{array}$ & $\begin{array}{lll} & \bar{\pi} & \\
i & + & 0\end{array}$ \\
\hline 苛 & 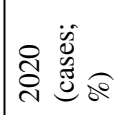 & 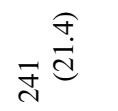 & 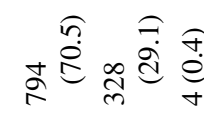 \\
\hline $\begin{array}{l}\vec{Z} \\
\bar{N} \\
\overline{0} \\
\infty\end{array}$ & 商苛 & 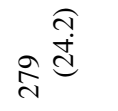 & 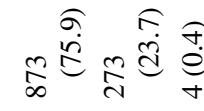 \\
\hline & ब & $\stackrel{\overbrace{}}{\stackrel{1}{0}}$ & 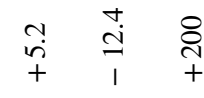 \\
\hline 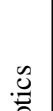 & 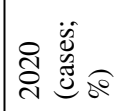 & $\begin{array}{l}\overparen{d} \\
\underset{d}{\Xi}\end{array}$ & 舟递 \\
\hline 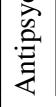 & 苍 & 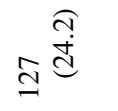 & 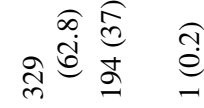 \\
\hline & 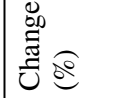 & & 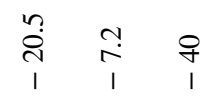 \\
\hline 恙 & 苍 & $\begin{aligned} & \stackrel{6}{d} \\
= & \mathbb{d}\end{aligned}$ & 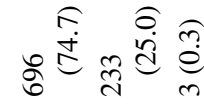 \\
\hline 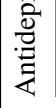 & 苍 & 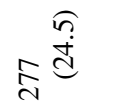 & 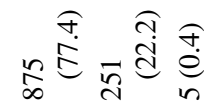 \\
\hline & ฮू & & $=\stackrel{0}{=}+\stackrel{0}{+} 0$ \\
\hline$\stackrel{\vec{E}}{\tilde{\Xi}}$ & 党 & $\stackrel{\substack{0 \\
\stackrel{d}{d}}}{0}$ & 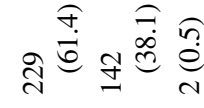 \\
\hline $\begin{array}{l}\tilde{0} \\
.0 \\
.0\end{array}$ & 总 & 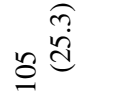 & 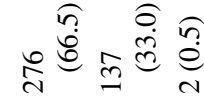 \\
\hline 券 & & 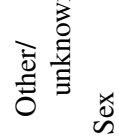 & 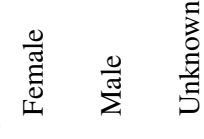 \\
\hline
\end{tabular}

phenobarbital, from 47 to 43 cases $(-8.5 \%)$ and topiramate, from 46 to 34 cases $(-26.1 \%)$. As it can be seen, benzodiazepines showed much less decrease than antidepressants in absolute numbers during the interval studied of quarantine. Clonazepam, the group's main representative, showed a decrease, from 749 to 686 cases $(-8.4 \%)$, while diazepam increased from 255 to 302 cases (+18.4\%). The main variation observed with antipsychotics were chlorpromazine, with an increased from 167 to 171 cases $(+2.4 \%)$ and risperidone, from 155 to 158 cases $(+1.9 \%)$.

Within this scenario, the reduction in medication for psychiatric treatment was mainly guided by a decrease in suicide attempts reaching a decline of $-9.8 \%$. As shown in Table 1, antidepressants presented a decrease of $-18.9 \%$ followed by anticonvulsants with $-14.2 \%$ and benzodiazepines with $-7.7 \%$ for suicide attempts. The analyzed data indicates a reduction on suicide attempt rates that can be correlated to a possible modulation within the intoxication profile of individuals due to social isolation, where people have been asked to stay confined within their homes with family and friends, which can be a protective factor associated with the occurrence of suicide attempts [6]. However, we observed an increase in the number of cases with recreational drugs as suicidal agents $(2019,101$ cases; 2020, 138 cases). In addition, the cases of self-medication increased for all classes of medicines evaluated in this study.

While quarantine can be effective in reducing the number of suicide attempts, the number of individual accidents has increased expressively (Table 1), mainly associated with recreational drugs, anticonvulsants, and benzodiazepines, especially accidents with children up to 5 years old. The age variable is one of the most relevant parameters, as it shows a clear tendency of who, in fact, is more vulnerable in these cases of intoxication. For instance, children aged $0-5$ years showed a serious increase in cases of intoxication by recreational drugs, of $+275 \%$, followed by more than $+30 \%$ in anticonvulsants and benzodiazepines. Much likely, due to the implementation of the isolation measures, which involved the closing of schools, resulting in children staying home for a much longer period. According to the results obtained, the use of recreational drugs during quarantine has increased, as well as the number of accidents associated with children and with the same compounds. Furthermore, individuals over 19 years old, showed a substantial increase in the consumption of recreational drugs, with $+48.0 \%$ and only $+3.0 \%$ in antipsychotics, as opposed to other classes which decreased, justifiable by a reduction in suicide attempts.

Considering the exposure site, cases at home had an expressive increase simply for recreational drugs. Despite the possibility of an increase in home poisonings, this number has not changed significantly, as most cases already occurred at home. However, in both the site and 
circumstance variables, large numbers that stood out were the "unknown" results, increasing in most classes, which causes serious difficulties for the medical staff to deal with in cases of intoxication since these variables are of extreme importance for a rapid and effective medical intervention.

Another variable that has considerably changed was gender. Within the recreational drugs group, for instance, cases involving women increased by $+80.3 \%$, while cases with men rose with $+17.0 \%$. Nonetheless, other classes showed a reduction in the number of female attendances and, curiously, male attendances in benzodiazepines and anticonvulsants increased, even considering the general decline of the groups.

In conclusion, we observed a change in the poisoning profile during quarantine, possibly due to the modification in habits and behavior of the population caused by social isolation. A significant increase in the incidence of cases by recreational drugs has been noted, in almost all aspects, while the cases involving medication for psychiatric use decreased, mainly because of the decline in suicide attempts, in a way as a possible protective effect. The statistics observed in 2020 contradicted our pre-pandemic period epidemiological data in 2019, indicating a strong influence of the quarantine. Therefore, the results show how the environment and social activities can modulate human behavior and that some factors such as gender and age can influence the intoxication profile. These numbers are of paramount importance for toxicovigilance and can be used as a projection for other states and countries because measures to prevent poisoning cases during quarantine can be adapted to reduce the damage caused indirectly by the outbreak of COVID- 19 .

Acknowledgments The authors would like to acknowledge the financial support from Coordination of Improvement of Personal Higher Education -Brazil [CAPES - Finance Code 001].

\section{Compliance with ethical standards}

Conflict of interest The authors declare that they have no conflict of interest.
Ethical approval This article does not contain any studies with human participants or animals performed by any of the authors.

\section{References}

1. Franco de Oliveira SCWSE, Zucoloto AD, de Oliveira CDR, Hernandez EMM, Fruchtengarten LVG, de Oliveira TF, Yonamine M (2019) A fast and simple approach for the quantification of 40 illicit drugs, medicines, and pesticides in blood and urine samples by UHPLC-MS/MS. J Mass Spectrom 54:600-611. https://doi. org/10.1002/jms.4369

2. Eller S, Zucoloto AD, de Oliveira CDR, Hernandes EMM, Fruchtengarten LVG, de Oliveira FNM, de Oliveir TF, Yonamine M (2020) Multivariate analysis applied in dataset of Poison Control Center of São Paulo, Brazil. Sci Rep 10:9498. https://doi. org/10.1038/s41598-020-66485-w (open access article)

3. Le Roux G, Sinno-Tellier S, French Poison Control Centre members, Descatha A (2020) COVID-19: home poisoning throughout the containment period [the corrected version first appears in Lancet Public Health, 2020 May 4]. Lancet Public Health 5:e314. https://doi.org/10.1016/S2468-2667(20)30095-5 (open access article)

4. Clay JM, Parker MO (2020) Alcohol use and misuse during the COVID-19 pandemic: a potential public health crisis? Lancet Public Health 5:e259. https://doi.org/10.1016/S2468-2667(20)30088 -8 (open access article)

5. Ornell F, Moura HF, Scherer JN, Pechansky F, Kessler FHP, von Diemen L (2020) The COVID-19 pandemic and its impact on substance use: implications for prevention and treatment. Psychiatry Res 289:113096. https://doi.org/10.1016/j.psychres.2020.113096 (open access article)

6. Reger MA, Stanley IH, Joiner TE (2020) Suicide mortality and coronavirus disease 2019-a perfect storm? JAMA Psychiatry. https://doi.org/10.1001/jamapsychiatry.2020.1060 (open access article)

Publisher's Note Springer Nature remains neutral with regard to jurisdictional claims in published maps and institutional affiliations. 